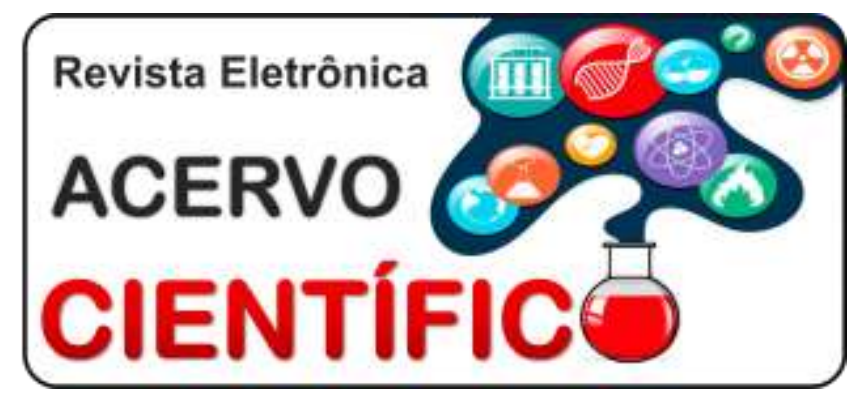

\section{ARTIGO ORIGINAL}

Recebido em: 10/2019

Aceito em: 11/2019

Publicado em: 12/2019

\title{
Pesquisa de coliformes totais e termotolerantes no rio Salgadinho no município de Juazeiro do Norte, CE
}

\author{
Research of total and thermotolerants coliforms in rio Salgadinho in the city of Juazeiro do \\ Norte, CE
}
Investigación de total coliformes y termotolerantes en el río Salgadinho en Juazeiro do Norte, CE

Likaele Moreira Nunes ${ }^{1 *}$, Maria de Fátima Guedes Monteiro ${ }^{1}$, Dárcio Luiz de Sousa Júnior ${ }^{2}$, Pedro Everson Alexandre de Aquino $^{3}$, Cícero Roberto Nascimento Saraiva ${ }^{1}$, Maria Karollyna do Nascimento Silva Leandro ${ }^{1}$, Ana Emília Formiga Marques ${ }^{4}$, Rakel Olinda Macedo da Silva, Lívia Maria Garcia Leandro'.

Resumo: Este estudo buscou analisar a qualidade bacteriológica da água do rio Salgadinho no município de Juazeiro do Norte, Ceará, por meio da pesquisa de coliformes totais e termotolerantes. As coletas foram feitas onde é evidente o despejo de resíduos domésticos e industriais, no período de agosto a setembro de 2016 com dez dias de intervalo entre cada uma. O procedimento de análise foi realizado em triplicata, utilizando o método de tubos múltiplos quantitativo ou número mais provável (NMP). Foram confirmados $100 \%$ de positividade para coliformes totais e coliformes termotolerantes em todas as amostras analisadas, com altas proporções registradas ( $\geq 1600 \mathrm{NMP} / \mathrm{ml}$ ). Isto indica que essas águas são impróprias para 0 banho e consumo, representando possíveis transmissoras de doenças de veiculação hídrica. Dessa forma, é imprescindível uma avaliação regular da água do rio, assim como, buscar conscientizar o poder público e moradores locais sobre à preservação e à importância do rio para a Região do Cariri.

Palavras-chave: Água, Rio, Coliformes, Qualidade.

\begin{abstract}
This study aimed to analyze the bacteriological quality of the Salgadinho river water in Juazeiro do Norte, Ceará, by researching total and thermotolerant coliforms. The collections were made where it is evident the dumping of domestic and industrial waste, from August to September 2016 with ten days apart. The analysis procedure was performed in triplicate using the quantitative or most probable number (MPN) multiple tube method. $100 \%$ positivity for total and thermotolerant coliforms was confirmed in all analyzed samples, with high proportions recorded $(\geq 1600 \mathrm{MPN} / \mathrm{mL})$. This indicates that these waters are unsuitable for bathing and consumption, representing possible transmitters of waterborne diseases. Thus, a regular assessment of river water is essential, as well as seeking to raise public awareness and local residents about the preservation and importance of the river for the Cariri Region.
\end{abstract}

Keywords: Water, River, Coliformes, Quality.

Resumen: Este estudio tuvo como objetivo analizar la calidad bacteriológica del agua del río Salgadinho en la ciudad de Juazeiro do Norte, Ceará, a través de la investigación de coliformes totales y termotolerantes.

${ }^{1}$ Centro Universitário Dr. Leão Sampaio (UNILEÃO), Juazeiro do Norte-Ceará. *E-mail: likaelemoreira@hotmail.com

2Universidade Regional do Cariri (URCA), Crato-Ceará.

3Universidade Federal do Ceará (UFC), Fortaleza-Ceará.

${ }^{4}$ Faculdade de Medicina Estácio de Juazeiro do Norte, Juazeiro do Norte-Ceará. 
Las recolecciones se realizaron donde es evidente el vertido de residuos domésticos e industriales, de agosto a septiembre de 2016 con diez días de diferencia. El procedimiento de análisis se realizó por triplicado utilizando el método de tubo múltiple de número cuantitativo o más probable (MPN). El $100 \%$ de positividad para coliformes totales y termotolerantes se confirmó en todas las muestras analizadas, con altas proporciones registradas $(\geq 1600 \mathrm{MPN} / \mathrm{mL}$ ). Esto indica que estas aguas no son aptas para el baño y el consumo, lo que representa posibles transmisores de enfermedades transmitidas por el agua. Por lo tanto, es esencial una evaluación periódica del agua del río, así como tratar de aumentar la conciencia pública y los residentes locales sobre la preservación e importancia del río para la región de Cariri.

Palabras-clave: Agua, Rio, Coliformes, Calidad.

\section{INTRODUÇÃO}

A água é uma substância indispensável à manutenção da vida, ela ocupa cerca de $70 \%$ da superfície do nosso planeta sendo encontrada nas formas sólida, líquida e gasosa. A maior parte da água presente em nosso planeta se encontra nos oceanos $(97,3 \%)$, restando apenas $2,7 \%$ de disponibilidade de água doce, não sendo de fácil acesso sua obtenção (LEME EJA, 2008).

Atualmente, encontrar fonte de água doce que não tenha suas características naturais alteradas pela interferência antrópica tem se tornado difícil, pois na maioria das atividades executadas pelo homem se faz a necessidade de água (SANTOS PP, 2010), comprometendo sua qualidade e quantidade disponível para utilização (AZEVEDO MN, et al., 2015), e consequentemente, prejuízos à saúde com impactos negativos (OLIVEIRA KL, et al., 2015).

O Brasil apresenta $12 \%$ da disponibilidade de água doce superficial do planeta. É um País que tem se tornado uma referência quanto à quantidade de água (BRASIL, 2012 e LIBÂNIO M, 2010), ou seja, políticas públicas adequadas devem garantir acesso à água de boa qualidade a todos (SCURACCHIO PA, 2010). A falta de saneamento básico em locais urbanos e rurais representa grande parte dos fatores de contaminação hídrica no Brasil, outro fator relacionado a contaminantes é a falta de proteção encontrada adjunta aos mananciais (SCAPIN D, et al., 2012).

Por meio da Portaria no 2.914/2011 do Ministério da Saúde foi estabelecido os procedimentos de controle e de vigilância da qualidade da água para consumo humano e seu padrão de potabilidade, tornando obrigatória a avaliação microbiológica nos pontos de captação dos mananciais superficiais, independentemente do seu princípio, sobressai-se que muitas das populações humanas usam fontes naturais e poços artesianos como forma de complementar o abastecimento de água (BRASIL, 2011a). A água pode comportar-se como um meio de transmissão para inúmeras doenças, representando um potencial infeccioso para quem a ingerir, é considerada um dos mais importantes veículos de enfermidades, o que torna primordial sua avaliação (ROSA AH, et al., 2012; SCALIZE PS, et al., 2014).

A utilização de bactérias do grupo coliforme é extremamente relevante para averiguar as condições sanitárias da água, em virtude do número elevado na flora intestinal de seres humanos e de animais de sangue quente, serem aplicáveis a todos os tipos de água, sobreviverem melhor que os possíveis patógenos, sendo responsáveis pela maioria das doenças de veiculação hídrica (RAMIRES CH, et al., 2009; DIAS AKD, et al., 2010; ALVES ICC, 2012).

As águas dos rios geralmente são usadas de diversas formas pelo ser humano, sendo necessário avaliálas, desde sua nascente até seu destino final, para que assim seja possível reconhecer os parâmetros em que elas se enquadram, assim como, conservação da bacia hidrográfica a qual pertencem (BATALHA SSA, et al., 2014; RATTI BA, et al., 2011).

O Rio Salgadinho está localizado no Estado do Ceará, situado principalmente na cidade de Juazeiro do Norte, abrange uma área de significativa importância para a cidade e municípios vizinhos, atualmente é alvo de lançamento inadequado de resíduos líquidos e sólidos. Diante desse contexto, o objetivo deste trabalho foi quantificar a presença de microrganismos do grupo dos coliformes, que torna inviável a água do Rio para o consumo. 


\section{MÉTODOS}

Por meio de uma pesquisa de caráter analítico-descritivo desenvolveu-se a avaliação quantitativa dos parâmetros microbiológicos relacionados a coliformes totais e fecais da água do rio Salgadinho no município de Juazeiro do Norte, Ceará. O município de Juazeiro do Norte, população estimada de 268.248 habitantes para 2016, está localizado na Região Metropolitana do Cariri (RMC), nas coordenadas geográficas 7ํ 12' 47" S e 39 18' 55" O (Sul do Ceará), compreende uma área de $248,832 \mathrm{~km}^{2}$, altitude de 377,3 metros, clima tropical quente semiárido brando com temperatura média de $24^{\circ} \mathrm{C}$ a $26^{\circ} \mathrm{C}$ (CEARÁ, 2015).

A abrangência desta pesquisa se estende à um trecho do Rio Salgado, na cidade de Juazeiro do Norte, Ceará. O referido rio nasce na fonte da Batateira, no sopé da Chapada do Araripe, município de Crato, onde é inicialmente denominado por rio Batateiras. No município de Juazeiro do Norte é denominado de rio Salgadinho, e neste município recebe contribuições dos afluentes Riachos dos Macacos e rio Carás (SABIÁ RJ, 2008).

Para se chegar ao objetivo do trabalho foram coletadas amostras de três pontos distintos de um trecho do rio Salgadinho, sendo o primeiro localizado no Bairro Areia Grossa (ponto A), o segundo no caminho (ponto B) que dá acesso ao Horto e o terceiro no intermédio (ponto C) dos dois primeiros, anteriormente, citados. Para maior confiabilidade dos resultados, as análises foram realizadas em triplicata. As amostras foram coletadas no período de agosto a setembro de $2016 \mathrm{com}$ intervalo de dez dias entre cada uma, no horário compreendido de 15:00 às 17:30 horas.

Para o procedimento da coleta seguiu-se corretamente o protocolo estabelecido por meio de técnica específica para águas superficiais, descrito no Guia Nacional de Coleta e Preservação de Amostras: Água, Sedimento, Comunidades Aquáticas e Efluentes Líquidos, documento este elaborado pela Companhia Ambiental do Estado de São Paulo (CETESB) em conjunto com a Agência Nacional de Águas - ANA (BRASIL, 2011b).

Foram utilizados frascos estéreis de vidro autoclavável com capacidade para $250 \mathrm{ml}$, que foram mergulhados rapidamente com a boca para baixo a uma profundidade de $15 \mathrm{~cm}$ a $30 \mathrm{~cm}$, direcionados em sentido contrário à correnteza, assegurando que fossem colhidos $100 \mathrm{ml}$ por cada frasco. Posteriormente as amostras foram acondicionadas em caixas isotérmicas sob refrigeração de $4^{\circ}$ a $10^{\circ} \mathrm{C}$ e encaminhadas ao laboratório de análises microbiológicas de água do Centro Universitário Dr. Leão Sampaio - UNILEÃO, campus saúde, para serem analisadas em até 24 horas.

Com o intuito de determinar e quantificar coliformes totais e termotolerantes fez-se uso da técnica do número mais provável (NMP), também conhecida como Tubos Múltiplos, empregando-se Caldo Lactosado duplo e Caldo Lactosado simples como teste presuntivo (incubação á $37^{\circ} \mathrm{C}$ por 48 horas) e como teste confirmativo o Caldo Lactosado Bile Verde Brilhante (CLBVB) para coliformes totais (incubação á $37^{\circ} \mathrm{C}$ por 48 horas) e o caldo Escherichia coli (EC) para coliformes termotolerantes (incubação a $44,5^{\circ} \mathrm{C}$ por 24 horas). A presença do grupo coliformes foi observada pela turvação do meio e formação de gás em tubos de Duhran (YAMAGUCHI MU, et al., 2013).

\section{RESULTADOS E DISCUSSÃO}

Por meio dos resultados das análises das amostras de água foi possível avaliar a qualidade bacteriológica da água do rio Salgadinho relacionada a Coliformes Totais e termotorelantes. Esses coliformes habitam o intestino de mamíferos, inclusive do ser humano, constituindo a flora normal do organismo sem causar doenças, e sua presença no ambiente aquático é indicativo de contaminação fecal, principalmente quando é detectada a presença de E. coli (OLIVEIRA AVB, 2011).

As principais bactérias do grupo coliforme pertencem aos gêneros Escherichia, Aerobacter, Citrobacter, Klebsiela e outros que quase nunca aparecem em fezes como a Serratia. Atualmente são considerados bioindicadores mais utilizados na avaliação da qualidade das águas, sendo parâmetro microbiológico básico incluído nas legislações relativas à água para consumo humano, assim como, no monitoramento da qualidade de águas destinadas a potabilidade e balneabilidade (BLINI RCB, 2015; DUARTE PB, 2011). 
Os resultados obtidos na análise das amostras coletadas no rio Salgadinho detectaram a presença de bactérias nas 48 horas do ensaio presuntivo, conduzindo o ensaio até o confirmativo que apresentou resultados positivos para bactérias do grupo coliformes totais e termotolerantes em $100 \%$ das amostras analisadas dos três pontos de coleta. O ensaio foi repetido e confirmado, onde se obteve com clareza a intensa contaminação do leito do rio.

Em relação aos coliformes totais, todas as amostram apresentam-se relevante nos dois meses de análise, com resultados acima de $1.600 \mathrm{NMP} / 100 \mathrm{~mL}$ (Tabela 1). Essa ocorrência pode ser esclarecida seguramente pelas más circunstâncias que o rio em toda sua extensão se encontra, fato esse que se correlaciona a presença de coliformes termotolerantes, confirmando a importância e a necessidade da preservação do rio e a necessidade do saneamento básico na cidade de Juazeiro do Norte. Discordantes com Portaria ํㅡ 2.914, de 12 de dezembro de 2011, em que dispõe que os coliformes termotolerantes devem estar ausentes em $100 \mathrm{ml}$ de amostra de água para ser considerada potável.

Tabela 1 - Resultados das análises bacteriológicas da água do rio Salgadinho realizadas em três pontos de coletas no período de agosto a setembro de 2016 por meio da técnica de tubos múltiplos, dados em NMP/100mL.

\begin{tabular}{lllllll}
\hline & Ponto A & \multicolumn{3}{c}{ Ponto B } & \multicolumn{3}{l}{ Ponto C } & \\
\hline & CT & CTe & CT & CTe & CT & CTe \\
\hline $1^{\text {a }}$ coleta & $\geq 1600$ & $\geq 1600$ & $\geq 1600$ & $\geq 1600$ & $\geq 1600$ & $\geq 1600$ \\
\hline $2^{\text {a }}$ coleta & $\geq 1600$ & $\geq 1600$ & $\geq 1600$ & $\geq 1600$ & $\geq 1600$ & $\geq 1600$ \\
\hline $3^{\text {a }}$ coleta & $\geq 1600$ & $\geq 1600$ & $\geq 1600$ & $\geq 1600$ & $\geq 1600$ & $\geq 1600$ \\
\hline
\end{tabular}

Legenda: CT: Coliformes Totais; CTe: Coliformes Termotolerantes. Fonte: Nunes LM, et al., 2016.

Ao longo deste estudo observou-se que moradias próximas ao rio Salgadinho, em área rural, são desprovidas de rede de esgoto, despejando justamente seus resíduos em numerosos pontos de escoamentos notados ao longo do rio, contribuindo para a poluição desse corpo d'água e culminado no aparecimento de doenças entéricas aos que vierem manusear essa água de forma direta ou indireta.

Fernandes GB et al. (2002) observaram vários sinais de autodepuração no Rio Salgado ao longo do trecho, conforme análises do teor de oxigênio dissolvido. Nesse mesmo estudo, os teores de nutrientes encontrados (nitrogênio amoniacal e ortofosfato solúvel) indicaram a existência de lançamentos de esgoto bruto no rio, revelando um grau de anaerobiose. Isso, provavelmente, tem contribuído para a mortandade de peixes e outros organismos aeróbios. Vale ressaltar que a decomposição dos compostos orgânicos por bactérias aeróbias contribui para redução do oxigênio dissolvido e degradação da qualidade da água (SIQUEIRA GW, et al., 2012).

Este é um problema bastante preocupante, pois o lançamento inadequado de resíduos líquidos e sólidos em rios tem contribuído bastante para que eles apresentem condições ou situações de risco que podem influenciar o padrão e nível de saúde de uma população (CESA MV e DUARTE GM, 2010). Outro dilema observado na área deste estudo é a situação do aterro sanitário do município de Juazeiro do Norte, pois ele se encontra instalado paralelamente ao rio, havendo possibilidade de infiltração das águas pluviais e, consequentemente, escoamento do chorume para o rio Salgadinho (PEREIRA CMC, 2005).

Considerando os resultados obtidos nesta pesquisa, de acordo com a Resolução CONAMA №357 de 17 de março de 2005, a água do rio Salgadinho é classificada como águas doces de classe III. Nesta resolução, para que o uso de recreação de contato secundário seja permitido, não deverá ser excedido um limite de 2500 coliformes termotolerantes por 100 mililitros e para os demais usos, não deverá ser excedido um limite de 4000 coliformes termotolerantes por 100 mililitros em $80 \%$ ou mais de pelo menos 6 amostras coletadas. Na literatura, há vários trabalhos que analisam qualitativa e quantitativamente diversos corpos de águas superficiais que são destinos de compostos orgânicos e/ou inorgânicos. Esses estudos, em sua maioria, descrevem resultados discordantes dos que são exigidos pela Resolução CONAMA 357/2005. No entanto, há casos em que seus dados demonstram total favorecimento a esta legislação. 
Prestes TMV, et al. (2011) quantificaram coliformes termotolerantes e totais presentes nas águas do rio Alegria e seu afluente rio Bolinha, na área urbana de Medianeira, PR, Brasil, por meio do método de fermentação em tubos múltiplos. Para todas as oito amostras analisadas, registraram-se $100 \%$ de positividade para coliformes totais, e em sete delas confirmou-se a presença de coliformes fecais. As altas proporções registradas em três pontos amostrais (4.600 NMP/mL; $930 \mathrm{NMP} / \mathrm{mL}$ e $750 \mathrm{NMP} / \mathrm{mL}$ ), indicaram que esses pontos são impróprios para o banho e possíveis transmissores de doenças, por terem ultrapassado os índices bacteriológicos descritos no Art. $2^{\circ}$ do CONAMA $n^{\circ} 274$, que trata de águas destinadas à balneabilidade.

O estudo realizado por Siqueira GW, et al. (2012) buscou desenvolver o Índice de Qualidade da água (IQA) de um trecho do rio Parauapebas, localizado no centro-sul do Estado do Pará. Nesse estudo, alguns dos parâmetros do IQA apresentaram-se discordantes com os valores permissíveis na Resolução do Conselho Nacional do Meio Ambiente (CONAMA) №357. O parâmetro microbiológico revelou ser a variável mais significativa para a interpretação da qualidade da água da bacia no trecho monitorado. Foram determinadas concentrações entre 200 e 1300 Número mais provável (NMP)/100 Mililitros (ml), com média de $650 \pm 207 \mathrm{NMP} / 100 \mathrm{ml}$, reforçando a questão de estar havendo contaminação por efluentes orgânicos na região, especialmente de origem doméstica, necessitando de atenção especial por parte dos administradores municipais no que tange ao saneamento básico.

Machado IBT, et al. (2013) avaliaram a qualidade microbiológica da água da Bacia de Manancial do Ribeirão Cafezal localizada nas cidades de Londrina, Cambé e Rolândia. Os resultados demonstraram concordância com os valores permissíveis pela legislação brasileira em vigor, e mesmo assim, houve presença constante de $E$. Coli, o qual é indicativo de contaminação recente, principalmente por esgotos domésticos.

A qualidade microbiológica das águas superficiais do rio Jucu Braço Sul, ES, foi estudada por Terra VR, et al. (2008). Nessa avaliação, as concentrações de coliformes termotolerantes apresentaram-se bastante variáveis ao longo do período de monitoramento, com todos os pontos amostrados, apresentando de contaminação, porém, dentro dos limites estabelecidos pelo CONAMA, referente à proteção à vida aquática e à recreação de contato primário. Contudo, está água não é recomendável para o consumo humano, a não ser, após tratamento convencional.

Portanto ressalvar que a água quando não passar por um tratamento adequado se torna fonte ativa de transmissão de doenças, ocasionalmente as doenças do trato gastrointestinal, sendo capaz de servir como meio de cultura para microrganismos patogênicos causando doenças àqueles que a ingerem, frequentemente crianças, pois ainda não possuem o hábito de higiene que possam evitar tais doenças. $O$ saneamento básico é um relevante fator que auxilia na prevenção desse tipo de situação, já que se trata de um conjunto de ações que tem como finalidade prevenir patologias tendo em vista uma maior qualidade de vida (RATTI BA, et al., 2011).

\section{CONCLUSÃO}

Diante dos dados obtidos neste estudo, entende-se que as águas do rio Salgadinho se encontram potencialmente contaminadas por coliformes termotolerantes, cujos valores transcendem a quantidade de 1600 por $100 \mathrm{ml}$ de água, desqualificando e indicando-a como imprópria para consumo podendo também se apresentar imprópria para a balneabilidade.

Diante disso, é imprescindível ação do poder público e prontidão privada para resolver esse problema socioambiental. Faz-se indispensável através deste estudo a execução de novas análises para monitoramento da profundidade desses índices de contaminação do rio Salgadinho.

Ressaltamos ainda a importância de realiza análise de parâmetro parasitológico, em virtude da possível existência de parasitas tais como, Schistosoma mansoni, Giardia lamblia e diversos tipos de amebíases. Sobretudo com a extensa área do rio salgadinho, destacamos que este é utilizado para irrigação de legumes e verduras a cerca de $33 \mathrm{~km}$ da cidade de Juazeiro do Norte. 
É imprescindível, também, conscientizar os moradores locais acerca das formas de manejo e cultivo da terra a fim de se preservar a mata ciliar presente, assim como, no que diz respeito ao despejo de resíduos sólidos nas margens e águas do Rio Salgadinho, enfatizando à importância desse corpo d'água para o município e região do Cariri.

\section{REFERÊNCIAS}

1. ALVES ICC, et al. Qualidade das águas superficiais e avaliação do estado trófico do Rio Arari (Ilha de Marajó, norte do Brasil). Acta Amazônica, 2012; 42(1): 115-124.

2. AZEVEDO MN, et al. Educação ambiental infantil: a importância da água. Anais do Salão Internacional de Ensino, Pesquisa e Extensão, 2015; 7(3): 1-2.

3. BATALHA SSA, et al. Condições físico-químicas e biológicas em águas superficiais do Rio Tapajós e a conservação de Floresta Nacional na Amazônia, Brasil. Revista Ambiente e Água, 2014; 9(4): 647-663, 2014.

4. BLINI RCB. Eficiência dos bioindicadores para avaliação na qualidade das águas superficiais da Lagoa Maior urbana de Três Lagoas/MS. 2015. 90p. Dissertação (Mestrado em Geografia) - Universidade Federal De Mato Grosso Do Sul, 2015.

5. BRASIL. Ministério do Meio Ambiente. Portaria oㅡ 2.914 de dezembro de 2011. Dispõe sobre os procedimentos de controle e de vigilância da qualidade da água para consumo humano e seu padrão de potabilidade. Diário Oficial da República Federativa do Brasil, Brasília-DF, 2011a.

CEARÁ. Instituto de Pesquisa e Estratégia Econômica do Ceará. Perfil Básico Municipal 2015: Juazeiro do Norte. IPECE, 2015.

6. CESA MV e DUARTE GM. A qualidade do ambiente e as doenças de veiculação hídrica. Revista Geosul, Florianópolis, 2010; 25(49): 63-78.

7. DIAS AKD, et al. Qualidade microbiológica da água de bebedouros destinada ao consumo humano. Revista Biociências, 2010; 16(2): 132-138.

8. DUARTE PB. Microrganismos indicadores de poluição fecal em recursos hídricos. 2011. 51p. Monografia (PósGraduação em Microbiologia do Instituto de Ciências Biológicas) - Universidade Federal de Minas Gerais, 2011.

9. FERNANDES GB, et al. Caracterização qualitativa das águas do Rio Salgado no município de Juazeiro do Norte, Ceará. In: Simpósio Ítalo Brasileiro de Engenharia Sanitária e Ambiental VI, 2002. Anais do VI Simpósio Ítalo Brasileiro de Engenharia Sanitária e Ambiental. Vitória: Centro de Ensino Tecnológico - CENTEC, 2002.

10. LEME EJA. Manual prático de tratamento de águas residuárias. 1 ed. São Paulo: Edufscar, 2008.

11. LIBÂNIO M. Fundamento de qualidade e tratamento de água. 3. ed. São Paulo: Átomo, 2010.

12. MACHADO IBT, et al. Identificação de bactérias do grupo termotolerantes e totais na bacia de manancial do Ribeirão Cafezal. Trabalho de Conclusão de Curso (Graduação em Engenharia Ambiental) - Universidade Tecnológica Federal do Paraná, 2013.

13. Ministério do Meio Ambiente. Agência Nacional de Águas. Guia Nacional de Coleta e Preservação de Amostras: Água, Sedimento, Comunidades Aquáticas e Efluentes Líquidos. Brasília: ANA, 2011b.

14. Ministério do Meio Ambiente. Conselho Nacional do Meio Ambiente. Resolução no 357, de 17 de março de 2005. Dispõe sobre Classificação dos corpos d'água e diretrizes ambientais para o seu enquadramento, bem como estabelece as condições e padrões de lançamento de efluentes. Diário Oficial da República Federativa do Brasil, Brasília, DF, n. 53, p. 58-63, 18 Mar. 2005.

15. OLIVEIRA AVB, et al. Padrões microbiológicos da carne de frango de corte - referencial teórico. Revista Verde (Mossoró - RN - Brasil), 2011; 6(3): 01-16.

16. OLIVEIRA KL, et al. Diagnóstico da percepção sanitária sobre a água na escola técnica estatual Benedito Storani (ETEC BEST) em Jundiaí. Atas de Saúde Ambiental - ASA, 2015; 3(2): 125-131.

17. PEREIRA CMC. Análise da problemática do lixo nas romarias em Juazeiro do Norte - CE. 2005, 164p. Dissertação (Mestrado), Pós-graduação em Desenvolvimento e Meio Ambiente, Área de Concentração - Ecologia e Organização do Espaço, Universidade Federal do Ceará, Fortaleza, 2005.

18. PRESTES TMV, et al. Análises microbiológicas das águas do rio alegria e de seu afluente rio bolinha do município de medianeira, Paraná, brasil. Revista de Ciências Ambientais, 2011; 5(2): 15-24.

19. RAMIRES $\mathrm{CH}$, et al. Influência da qualidade microbiológica da água sobre a qualidade do leite. Archives of Veterinary Science, 2009; 14(1): 36-42, 2009.

20. RATTI BA, et al. Pesquisa de coliformes totais e fecais em amostras de água coletadas no bairro zona sete, na cidade de Maringá-PR. VII EPCC - Encontro Internacional de Produção Científica Cesumar. Editora CESUMAR. 2011.

21. ROSA AH, et al. Meio ambiente e sustentabilidade. 1 ed. Porto Alegre: Bookman, 2012. 
22. SABIÁ RJ. Estudo do Padrão de Emissão de Poluentes para o Enquadramento de Rios Intermitentes: Estudo de caso do Rio Salgado, Ce. 2008, 137p. Tese, (Área de Concentração-Saneamento Ambiental). Universidade Federal do Ceará, Fortaleza-CE, 2008.

22. SANTOS PP, et al. Qualidade microbiológica de afluentes e efluentes de estações de tratamento de água e esgoto de Goiânia, Goiás. Revista de Patologia Tropical, 2010; 39(3): 173-187.

23. SCALIZE PS, et al. Avaliação da qualidade da água para abastecimento no assentamento de reforma agrária Canudos, Estado de Goiás. Revista Ambiente e Água, 2014; 9(4):696-707.

24. SCAPIN D, et al. Qualidade microbiológica da água utilizada para consumo humano na região do extremo oeste de Santa Catarina, Brasil. Revista Instituto Adolfo Lutz, 2012; 71(3):593-6

25. SCURACCHIO PA. Qualidade da água utilizada para consumo em escolas no município de São Carlos - SP. 2010. 57p. Dissertação (Pós-Graduação em Alimentos e Nutrição) - Universidade Estadual Paulista, Araraquara-SP, 2010.

26. SIQUEIRA GW, et al. Diagnóstico da qualidade da água do rio Parauapebas (Pará - Brasil). Acta Amazônica, 2012; 42(3): $413-422$.

27. TERRA VR, et al. Avaliação microbiológica das águas superficiais do rio Jucu Braço Sul, ES, Brasil. Natureza on line, 2008; 6(1):48-52.

28. YAMAGUCHI MU, et al. Microbiological quality of human consumption water in a school in Maringa-PR. O Mundo da Saúde, 2013; 37(3): 312-320. 